\section{Well-being and Perfectionism in Students: Adaptive versus Maladaptive}

Iranian Evolutionary and Educational

Psychology Journal

September 2019: 222-230

(C) University of Hormozgan Publication 2019

DOI: 10.29252/ieepj.1.3.222

http://ieepj.hormozgan.ac.ir

\author{
Reza Fallahchai ${ }^{1}$, Maryam Fallahi ${ }^{2 *}$ and Arefeh Moazen Jami ${ }^{3}$
}

\begin{abstract}
The prevalence of perfectionism among university students has been reported particularly high, and new theories have been presented to explain its impacts. This study was conducted to evaluate the effect of adaptive and maladaptive perfectionism on psychological well-being in undergraduate and graduate university students. 668 university students (386 undergraduate and 282 graduate students) who studied at Shahid Chamran University of Ahvaz and Shiraz University participated voluntarily in this study. They completed the Revised Almost Perfect Scale (APS-R) questionnaire and Ryff's Well-Being Scale. The results showed that the mean scores of adaptive perfectionist students in the psychological well-being and its sub-scales, autonomy, purpose in life, positive relations with others, and environmental mastery, were higher than the group of students with maladaptive perfectionist and non- perfectionist. The statistically significant difference was found $(\mathrm{P}<0.01)$. As a result, it can be said that adaptive perfectionist is accompanied by better and higher performance and consequently leads to a higher psychological well-being.
\end{abstract}

Keywords:Adaptive perfectionist, maladaptive perfectionist, Psychological well-being, University Students.

\title{
Introduction
}

Perfectionism is a complex construct that reflects cognitive, emotional, and behavioral factors and processes (Sherry, Hewitt, Flett, Lee-Baggley, \& Hall, 2007) and is defined as the tendency to strive for perfection and evaluation, judgment, and individuals' definition according to very high standards determined by themselves and / or society (Franche, Gaudreau, \& Miranda, 2012). According to some experts, perfectionism is not something that people have or not. It is a concept that all of us experience in varying degrees (Egan, Wade, Shafran, \& Antony, 2014), while the others believe that perfectionism is a prominent personality trait (Damian, Stoeber, Negru $\square$ Subtirica, \& Băban, 2017). According to the researchers, perfectionism is viewed as a personality tendency that has been characterized by trying to be flawless and have high standards of extreme performance (Flett \& Hewitt, 2002), a tendency that influences all aspects of life, especially work and education (Stoeber, 2012). Generally, perfectionism is defined as a condition in which a person has extremely high personal standards and tends to have a highly critical review of his/her behavior and personal success (Stoeber, Feast, \& Hayward, 2009).

Recent research suggests that perfectionism is a multi-dimensional construct and consists of both positive and negative qualities (Chufar \& Pettijohn, 2013). Hewitt et al. (2003) defined perfectionism in three dimensions: Self-oriented perfectionism (SOP); willing to set standards for self; evaluate and sharply criticize his/her behavior); Other-oriented perfectionism (OOP): tend to set standards for others and evaluate and sharply criticize the behavior of others; and Socially prescribed perfectionism (SPP): the belief that prominent people have unrealistic expectations and they need to meet the high standards of others.

1. Department of Consultant \& Psychology, Faculty of Human Sciences, University of Hormozgan, Bandar Abbas, Iran

2. Department of Consultant \& Psychology, Faculty of Human Sciences, University of Hormozgan, Bandar Abbas, Iran, *Corresponding author Email: fallahi.phd@,hormozgan.ac.ir

3. MA in Family Counselling, Department of Consultant \& Psychology, Faculty of Human Sciences, University of Hormozgan, Bandar Abbas, Iran 
Stoeber and Otto (2006) reported that perfectionism is composed of two higher factors: perfectionistic strivings and perfectionistic concerns. According to Damian et al. (2017) perfectionistic strivings (or personal standards) reflect aspects of perfectionism accompanied by self-oriented perfectionism and setting very high personal standards for performance. Perfectionistic concerns or evaluation concerns (ES) merge the aspects of perfectionism associated with fear of making mistakes or negative judgment of others, the tendency to show a negative reaction to deficiency and fault, and aspects related to feelings of the inconsistency between expectations and performance of an individual.

According to Bong, Hwang, Noh, and Kim (2014), both dimensions of perfectionism, especially considering the differential relationship between motivation and beliefs, and behaviors related to success have important consequences in terms of training. In the past, the most common viewpoint were often considered perfectionism as an evidence of maladjustment (Flett \& Hewitt, 2002; Thorpe \& Nettelbeck, 2014), while the positive or adaptive perfectionism indicates that attempts to perfection are associated with positive characteristics and satisfactory and acceptable outcomes (Glynn Owens \& Slade, 2008; Stoeber \& Otto, 2006; Stoeber \& Rambow, 2007).

For example, research has shown that perfectionist strivings are associated with efficiency and higher academic achievement in education (Stoeber, 2012). A large number of studies have supported adaptive/maladaptive dichotomy (Gilman \& Ashby, 2003; Stoeber, Kempe, \& Keogh, 2008; Trumpeter, Watson, \& O’Leary, 2006). Adaptive perfectionism have been associated with psychological adjustment (Miquelon, Vallerand, Grouzet, \& Cardinal, 2005), more positive forms of self-esteem regulation (Trumpeter et al., 2006), higher self-esteem (Chufar \& Pettijohn, 2013) and willingness to do challenging work and higher average at university or school (Bieling, Israeli, Smith, \& Antony, 2003; Slaney, Rice, Mobley, Trippi, \& Ashby, 2001). Negative or maladaptive perfectionism is related to fear of failure, physical symptoms (Stoeber \& Rambow, 2007), suicide risk (O'Connor, 2007), eating disorders, hopelessness and insomnia(Bieling, Israeli, \& Antony, 2004; Rice, Richardson, \& Clark, 2012), and anxiety disorders and depression (Iarovici, 2014).

Results in high levels of perfectionism are inconsistent. For example, high levels of perfectionism have been known as a factor in increasing vulnerability to depression (Gilbert et al., 2010; McEwan, Gilbert, \& Duarte, 2012). While other research results show that determining high personal standards for performance is generally defined as a central aspect of perfectionism, but is not usually considered as a maladaptive perfectionism (Flett \& Hewitt, 2002; Slaney, Rice, \& Ashby, 2002; Stoeber \& Otto, 2006).

One of the important variables concerning perfectionism is psychological well-being (Bulina, 2014; Kenny \& Hicks, 2014). Psychological well-being can be defined as emotional and cognitive reactions to perceived personal characteristics and abilities, and positive and efficient interaction with the world, good relationship with the community and positive progress over time, which can include components such as: life satisfaction, positive energy and mood (Karademas, 2006). Psychological well-being has been described not only as the absence of mental disorders (Sin \& Lyubomirsky, 2009), but as the presence of positive psychological resources consists of subjective well-being (e.g. positive affect, life satisfaction, happiness) as well as components of eudemonic well-being happiness and personal well-being (e.g. self-acceptance, positive relationships, autonomy, purpose in life) (Ryan \& Deci, 2001). Well-being is a key measure of mental health and it has been shown that it is associated with many positive factors, such as: increase in physical health (Bartram \& Boniwell, 2007; Cohen, 2003); optimal performance (Davidson, 2003); reduction of psychological problems; skills of having the sense of responsibility and even long life (Danner, Snowdon, \& Friesen, 2001). Psychological well-being is related to the people's reactions to the pressures of everyday life (Ryff \& Keyes, 1995) which contains emotions and people's everyday assessments of their lives (Heeman, 2008; Lyubomirsky, Dickerhoof, Boehm, \& Sheldon, 2011).

The prevalence of perfectionism among university students is reported high (Rice \& Ashby, 2007); therefore the problems caused by it have the relatively high frequency (Grzegorek, Slaney, Franze, \& Rice, 2004). For example, Kornblum and Ainley (2005) reported levels of perfectionism among distinguished students higher than average students. On the other hand, some theorists believe that perfectionism is a unique and important form and sign of personality dysfunction (Flett \& Hewitt, 2002), so, perfectionism can be considered as a risk factor for psychological well-being (Sirois \& Molnar, 2016). However, other theorists believe that perfectionism include adaptive component that can improve psychological well-being (Flett \& Hewitt, 2006; Sirois \& Molnar, 2016; Stoeber \& Otto, 2006). 
With regard to the relationship between perfectionism and negative consequences, such as depression (Rice \& Ashby, 2007), other research suggests that students with high depressive symptoms are less likely to graduate (Wintre \& Bowers, 2007). As a result, continuous examination of perfectionism amongst students is considered an important effort. Furthermore, due to the levels of perfectionism among distinguish students that is higher than ordinary students, and on the other hand, few studies on the perfectionism among students considering different levels of education (graduate, undergraduate, and Ph.D.) and gender differentiation, this study is a necessity, and as a result, this study is one of the first studies in this field in Iran. Finally, studies on the relationship between psychological well-being and perfectionism in Western countries have reported different and mixed results (Rice \& Stuart, 2010), so it is necessary to study this issue in the country. The main hypotheses in the present research included:

Hypothesis 1: There would be significant differences between the adaptive perfectionist, maladaptive and non- perfectionist university students in psychological well-being.

Hypothesis2: There would be significant differences between the adaptive perfectionist, maladaptive and non- perfectionism university students in the subscales of psychological well-being.

\section{Material and Methods \\ Participants}

The population consisted of undergraduate and graduate students of Shahid Chamran University of Ahvaz and Shiraz University in the academic year 94-95 that voluntarily participated in this study. The total number of students participating was 668 (340 males and 328 females) and 386 of them were undergraduate while 282 were M.A or Ph.D. students in the faculties of Humanities, Engineering, Agriculture, and the Basic Sciences. Mean age of the participants was 23.4 with a standard deviation of 8.3.

\section{Tools}

Revised Almost Perfect Scale (APS-R): For measuring the multidimensional structure of perfectionism, Revised Almost Perfect Scale was used (Slaney et al., 2001). APS-R has 23 items with three subscales: "High Standards" (7 items), "Discrepancy" (12 items), and "Order" (4 items). Participants rate their success on a 7-point Likert scale ranging from 1 (strongly agree) to 7 (strongly disagree). The High Standards subscale measures the high standards for achievement and performance (e.g., "I have high expectations for myself "). The Order subscale measures a tendency for neatness and orderliness (e.g., "I am an orderly person."). The Discrepancy subscale measures the degree to which people perceive themselves as failing to meet their standards for performance (e.g., "Doing my best never seems to be enough."). Slaney et al. (2001) performed a series of exploratory and confirmatory factor analyses which supported the factor structures. They structural coefficients were ranging from 0.49 to 0.86 . Numerous other studies supported the factor structures of APS-R. Slaney et al. (2001) confirmed convergent and discriminant validity of the scale. They reported that cronbach's coefficient alphas for separate samples were perfectly appropriate: High standards $(0.85,0.85)$, Disparities $(0.92,0.91)$ and order $(0.86,0.85)$. The test-retest correlations of the subscales (for intervals of 3 weeks to 10 weeks) varied from $r=.72$ to $r=.87$ ((Grzegorek et al., 2004; Rice \& Aldea, 2006).

Ryff's Well-Being Scale: This scale was designed by Ryff in 1980. The first form consisted 120 items; however, shorter forms including 84, 54, and 11 items were also suggested in next studies (Ryff \& Keyes, 1995). The 84-item form was utilized in the current study. The scale is made of six subscales: self-acceptance, positive relations with others, autonomy, purpose in life, personal growth, and environmental mastery. Each subscale had 14 items that were measured using a 6-point Likert scale ranging from $1=$ totally disagree through to $6=$ totally agree. The minimum and maximum ratings were 84 and 504, respectively. The higher ratings showed higher psychological well-being in each of these 6 subscales. Ryff (1989) reported the scale's coefficient of reliability between 0.83 and 0.91 . The internal consistency of this scale was reported to range from 0.82 to 0.90 (Schmutte \& Ryff, 1997). In another study conducted by Van Dierendonck (2004), it would range from 0.77 to 0.90 . The results of a research conducted on a student sample in Iran indicated that the internal consistency, with the use of Cronbach's alpha coefficient, were $0.69,0.74,0.65,0.73,0.65,0.60$, and 0.90 for environmental mastery, personal growth, positive relations with others, purpose in life, self-acceptance, autonomy, and the total score, respectively (Mikaeili, 2010). In the current study, Cronbach's alpha coefficients were calculated and reported to be $0.82,0.83,0.82,0.90,0.90,0.86$, and 0.88 for environmental 
mastery, personal growth, positive relations with others, and purpose in life, self-acceptance, autonomy, and the total score, respectively.

\section{Results}

Table 1 shows the standard deviation and mean of components of Adaptive, Maladaptive, and Non-Perfectionist groups as well as Psychological Wellbeing. As the results showed, the mean scores of the adaptive group in all subscales of Psychological Wellbeing were higher than the other two groups, while the mean scores of the Maladaptive and Non-Perfectionist groups did not differ significantly in these subscales.

Table 1. Means and SD for SWLS for Adaptive, Maladaptive and Non-Perfectionist Groups

\begin{tabular}{|l|c|c|c|c|c|c|}
\hline Variables & \multicolumn{2}{|c|}{ Adaptive perfectionist } & \multicolumn{2}{|c|}{ Maladaptive perfectionist } & \multicolumn{2}{l|}{ Non-perfectionist } \\
\hline & $\mathrm{M}$ & $\mathrm{SD}$ & $\mathrm{M}$ & $\mathrm{SD}$ & $\mathrm{M}$ & SD \\
\hline Psychological Wellbeing & 97.84 & 11.34 & 81.50 & $12 / 11$ & 81.60 & 13.61 \\
\hline Autonomy & 17.96 & 2.372 & 14.84 & 2.153 & 14.74 & 2.284 \\
\hline Personal Growth & 14.80 & 2.349 & 14 & 2.264 & 13.30 & 2.143 \\
\hline Purpose in Life & 16.41 & 2.444 & 12.16 & 2.335 & 13.21 & 2.182 \\
\hline positive relation with others & 16.90 & 2.414 & 14.76 & 2.313 & 14.01 & 2.170 \\
\hline Self-acceptance & 14.24 & 2.285 & 12.53 & 2.215 & 12.48 & 2.117 \\
\hline Environmental Mastery & 16.79 & 2.404 & 12.96 & 2.305 & 13.84 & 2.196 \\
\hline
\end{tabular}

In order to examine the first hypothesis of the research, whether there would be significant differences among groups, a multivariate analysis of variance (MANOVA) was run. Since one of the assumptions of using this analysis is to observe covariance matrices of the dependent variables, Box's M test was performed. The results indicated that the covariance matrices of the dependent variables were equal across groups $(\mathrm{F}=0.22, \mathrm{P}=0)$. Levene's test for homogeneity of variance was conducted. Results indicated that the variances of the three groups were equal $(\mathrm{F}=7.11, \mathrm{P}=0.64)$. The multivariate result was significant for groups, Pillai's Trace $=.401$, $\mathrm{F}=5.348, \mathrm{p}=.0001$, indicating a difference in psychological well-being across the groups.

Table 2. Results of Multivariate Analysis Of Variance (MANOVA)

\begin{tabular}{|l|c|c|c|c|c|}
\hline Indexes & Value & F & Hypothesis df & Error df & Sig. \\
\hline Pillai's Trace & .401 & 5.348 & 12.000 & 256.000 & 0.0001 \\
\hline Wilks'Lambda & .617 & 5.348 & 12.000 & 256.000 & 0.0001 \\
\hline Hotelling's Trace & .591 & 5.348 & 12.000 & 256.000 & 0.0001 \\
\hline Roy's Largest Root & .591 & 5.348 & 12.000 & 256.000 & 0.0001 \\
\hline
\end{tabular}

The results of Table 3 revealed significant differences across these three groups of students in psychological well-being and subscales including: autonomy, purpose in life, positive relations with others, and environmental mastery $(\mathrm{P}<0.01)$.

Table 3. Results of ANOVA Test Comparing the Means of Psychological Well-being and its subscales

\begin{tabular}{|l|l|c|c|c|c|c|}
\hline Source & Dependent Variable & SS & df & MS & F & Sig. \\
\hline group & Psychological Wellbeing & 857.659 & 2 & 428.83 & 92.11 & 0.001 \\
\hline & Autonomy & 272.593 & 2 & 136.296 & 8.636 & 0.01 \\
\hline & Personal Growth & 200.607 & 2 & 100.30 & 2.059 & 0.151 \\
\hline & Purpose in Life & 145.126 & 2 & 72.563 & 3.876 & 0.01 \\
\hline & positive relation with others & 236.548 & 2 & 118.274 & 27.281 & 0.01 \\
\hline & Self-acceptance & 43.793 & 2 & 21.896 & .988 & 0.21 \\
\hline
\end{tabular}

It was hypothesized that the significant there would be the significant differences between the adaptive perfectionist, maladaptive and non- perfectionism university students in the subscales of psychological well-being. In order to find out which pairs of means would be significant, Scheffe post-hoc test was used. The results are presented in Table 4. 
Table 4. Results of Scheffe post-hoc test for Psychological Wellbeing and its subscales in studied groups

\begin{tabular}{|c|c|c|c|c|c|}
\hline Dependent Variable & (I) group & (J) group & $\begin{array}{c}\text { Mean Difference } \\
\text { (I-J) }\end{array}$ & Std. Error & Sig. \\
\hline \multirow[t]{2}{*}{$\begin{array}{l}\text { Psychological Well- } \\
\text { being }\end{array}$} & Adaptive & $\begin{array}{l}\text { Maladaptive } \\
\text { Non-perfectionist }\end{array}$ & $\begin{array}{r}16.34 \\
16.24 \\
\end{array}$ & $\begin{array}{l}0.792 \\
0.788 \\
\end{array}$ & $\begin{array}{l}0.001 \\
0.001 \\
\end{array}$ \\
\hline & Maladaptive & Non-perfectionist & 0.1 & 0.317 & 0.818 \\
\hline \multirow[t]{2}{*}{ Autonomy } & Adaptive & $\begin{array}{l}\text { Maladaptive } \\
\text { Non-perfectionist }\end{array}$ & $\begin{array}{l}3.12 \\
3.22 \\
\end{array}$ & $\begin{array}{l}.466 \\
.402 \\
\end{array}$ & $\begin{array}{l}0.01 \\
0.01 \\
\end{array}$ \\
\hline & Maladaptive & Non-perfectionist & 0.1 & .320 & .31 \\
\hline \multirow[t]{2}{*}{ Personal Growth } & Adaptive & $\begin{array}{l}\text { Maladaptive } \\
\text { Non-perfectionist }\end{array}$ & $\begin{array}{l}0.80 \\
1.5 \\
\end{array}$ & $\begin{array}{l}.437 \\
.377 \\
\end{array}$ & $\begin{array}{l}0.146 \\
0.090\end{array}$ \\
\hline & Maladaptive & Non-perfectionist & 0.7 & .30 & .054 \\
\hline \multirow[t]{2}{*}{ Purpose in Life } & Adaptive & $\begin{array}{l}\text { Maladaptive } \\
\text { Non-perfectionist }\end{array}$ & $\begin{array}{l}4.25 \\
3.2 \\
\end{array}$ & $\begin{array}{l}.556 \\
.479 \\
\end{array}$ & $\begin{array}{l}0.01 \\
0.01 \\
\end{array}$ \\
\hline & Maladaptive & Non-perfectionist & -1.05 & .381 & .022 \\
\hline \multirow[t]{2}{*}{$\begin{array}{l}\text { positive relation with } \\
\text { others }\end{array}$} & Adaptive & $\begin{array}{l}\text { Maladaptive } \\
\text { Non-perfectionist }\end{array}$ & $\begin{array}{l}2.14 \\
2.89 \\
\end{array}$ & $\begin{array}{l}.519 \\
.447 \\
\end{array}$ & $\begin{array}{l}.093 \\
.000 \\
\end{array}$ \\
\hline & Maladaptive & Non-perfectionist & 0.75 & .356 & .122 \\
\hline \multirow[t]{2}{*}{ Self-acceptance } & Adaptive & $\begin{array}{l}\text { Maladaptive } \\
\text { Non-perfectionist }\end{array}$ & $\begin{array}{l}1.71 \\
1.76 \\
\end{array}$ & $\begin{array}{l}.357 \\
.308 \\
\end{array}$ & $\begin{array}{l}0.20 \\
.280 \\
\end{array}$ \\
\hline & Maladaptive & Non-perfectionist & 0.05 & .245 & .979 \\
\hline \multirow[t]{2}{*}{$\begin{array}{l}\text { Environmental Mas- } \\
\text { tery }\end{array}$} & Adaptive & $\begin{array}{l}\text { Maladaptive } \\
\text { Non-perfectionist }\end{array}$ & $\begin{array}{l}3.83 \\
2.96 \\
\end{array}$ & $\begin{array}{l}.506 \\
.436 \\
\end{array}$ & $\begin{array}{l}0.01 \\
0.01 \\
\end{array}$ \\
\hline & Maladaptive & Non-perfectionist & -0.88 & .347 & .040 \\
\hline
\end{tabular}

The findings reported in Table 4 indicated that in all sub-scales, the mean scores of students in the adaptive perfectionism group were higher than the mean scores of students in the maladaptive group and the non-perfectionist group. In order to determine if this difference was statistically significant, Sheffe's post- hoc test was run. The results showed that the mean scores of adaptive perfectionist students in the total score of psychological well-being and its sub-scales including: autonomy, purpose in life, positive relations with others, and environmental mastery was greater than the mean scores of the students in other groups and this difference was statistically significant $(\mathrm{P}<0.01)$. Furthermore, although students with adaptive perfectionism had a higher score in the sub-scales of personal growth and self-acceptance than the other two groups, this difference was not statistically significant. Another important finding presented in this table is that the mean scores of two groups of students in maladaptive and non-perfectionist groups on the total score of psychological well-being and its subscales were very similar, and no significant difference was observed.

\section{Discussion}

The aim of this study was to investigate the effect of perfectionism on psychological well-being in undergraduate and graduate students. Students' performance on the perfectionism scale (APS-R) was categorized into three groups: Adaptive, Maladaptive, and Non-Perfectionist. 
The first hypothesis concerning the significant differences in the psychological well-being among the three groups, Adaptive, Maladaptive, and Non-Perfectionist, was supported. Results demonstrated that the adaptive group of students had a higher level of well-being than maladaptive and Non-Perfectionist and the difference were statistically significant. This finding is consistent with the results of research (Bulina, 2014; Flett \& Hewitt, 2006; Kenny \& Hicks, 2014), and Sirois and Molnar (2016), but this result is inconsistent with Grzegorek et al. (2004) and Rice and Ashby (2007) studies.

In explaining this finding, it can be said that perfectionism is a construct that we all experience in different degrees (Egan et al., 2014), thus each of the different levels of perfectionism will have different effects on psychological well-being and individual performance and have influence in all life aspects (Stoeber et al., 2009). Therefore, it can be expected that individuals with adaptive perfectionism have higher psychological well-being than those with maladaptive and non-perfectionist. Furthermore, the findings of this study support Stoeber (2012) theory. This theory states that the perfectionist construct is composed of two higher-ranking factors: perfectionistic strivings (or adaptive perfectionism) and perfectionistic concerns (or maladaptive perfectionism).

Damian et al. (2017) state that adaptive perfectionism accompanied with better and higher functions leading to higher psychological well-being, while maladaptive perfectionist threatens the psychological well-being and mental health of the individual with fear and concern for making mistakes and misunderstanding or negative judgment of others, and tendency to react negatively to flaws. On the other hand, recent research has suggested that perfectionism includes both positive and negative qualities (Chufar \& Pettijohn, 2013). Also, studies show that perfectionism involves an adaptive component that improves psychological well-being (Flett \& Hewitt, 2006; Sirois \& Molnar, 2016; Stoeber \& Otto, 2006).

The study of the second hypothesis showed that university students with adaptive perfectionism had higher mean scores in the sub-scales of psychological well-being, autonomy, purpose in life, positive relations with others, and environmental mastery than those with maladaptive and non-perfectionist students, and this difference was statistically significant. Also, although students with adaptive perfectionism had a higher score in the sub-scales of personal growth and self-acceptance than the other two groups, this difference was not statistically significant. More so, although students with adaptive perfectionism had a higher score in the subscales of personal growth and self-acceptance than the other two groups, this difference was not statistically significant.

Another important result of this study was that there was no significant difference between the two groups of students with maladaptive and non-perfectionist neither in the total mean score of psychological well-being nor in any of the subscales of psychological well-being and their mean scores were very close.

\section{Declaration of Conflicting Interests}

The author(s) declared no potential conflicts of interest with respect to the research, authorship, and/or publication of this article.

\section{Funding}

The author(s) received no financial support for the research, authorship, and/or publication of this article.

\section{References}

Bartram, D., \& Boniwell, I. (2007). The science of happiness: achieving sustained psychological wellbeing. IN PRACTICE-LONDON-BRITISH VETERINARY ASSOCIATION-, 29(8), 478.

Bieling, P. J., Israeli, A., Smith, J., \& Antony, M. M. (2003). Making the grade: The behavioural consequences of perfectionism in the classroom. Personality and Individual Differences, 35(1), 163-178.

Bieling, P. J., Israeli, A. L., \& Antony, M. M. (2004). Is perfectionism good, bad, or both? Examining models of the perfectionism construct. Personality and Individual Differences, 36(6), 1373-1385.

Bong, M., Hwang, A., Noh, A., \& Kim, S.-i. (2014). Perfectionism and motivation of adolescents in academic 
contexts. Journal of educational psychology, 106(3), 711.

Bulina, R. (2014). Relations Between Adaptive and Maladaptive Perfectionism, Self-Efficacy, and Subjective Well-Being. Psychology Research, 4(10).

Chufar, B. M., \& Pettijohn, T. (2013). Meeting high standards: The effect of perfectionism on task performance, self-esteem, and self-efficacy in college students. Psychol. Behav. Sci, 2, 117-123.

Cohen, S. (2003). Psychosocial models of the role of social support in the etiology of physical disease.

Damian, L. E., Stoeber, J., Negru-Subtirica, O., \& Băban, A. (2017). On the development of perfectionism: The longitudinal role of academic achievement and academic efficacy. Journal of personality, 85(4), 565577.

Danner, D. D., Snowdon, D. A., \& Friesen, W. V. (2001). Positive emotions in early life and longevity: findings from the nun study. Journal of personality and social psychology, 80(5), 804.

Davidson, R. J. (2003). Affective neuroscience and psychophysiology: toward a synthesis. Psychophysiology, 40(5), 655-665.

Egan, S. J., Wade, T. D., Shafran, R., \& Antony, M. M. (2014). Cognitive-behavioral treatment of perfectionism: Guilford Publications.

Flett, G. L., \& Hewitt, P. L. (2002). Perfectionism and maladjustment: An overview of theoretical, definitional, and treatment issues.

Flett, G. L., \& Hewitt, P. L. (2006). Positive versus negative perfectionism in psychopathology: A comment on Slade and Owens's dual process model. Behavior Modification, 30(4), 472-495.

Franche, V., Gaudreau, P., \& Miranda, D. (2012). The $2 \times 2$ model of perfectionism: A comparison across Asian Canadians and European Canadians. Journal of Counseling Psychology, 59(4), 567.

Gilbert, P., McEwan, K., Irons, C., Bhundia, R., Christie, R., Broomhead, C., \& Rockliff, H. (2010). Self-harm in a mixed clinical population: The roles of self-criticism, shame, and social rank. British Journal of Clinical Psychology, 49(4), 563-576.

Gilman, R., \& Ashby, J. S. (2003). A first study of perfectionism and multidimensional life satisfaction among adolescents. The Journal of Early Adolescence, 23(2), 218-235.

Glynn Owens, R., \& Slade, P. D. (2008). So perfect it's positively harmful? Reflections on the adaptiveness and maladaptiveness of positive and negative perfectionism. Behavior Modification, 32(6), 928-937.

Grzegorek, J. L., Slaney, R. B., Franze, S., \& Rice, K. G. (2004). Self-Criticism, Dependency, Self-Esteem, and Grade Point Average Satisfaction Among Clusters of Perfectionists and Nonperfectionists. Journal of Counseling Psychology, 51(2), 192.

Heeman, V. C. (2008). Interpersonal communication motives, satisfaction, and psychological well-being in father-young adult daughter relationships. Kent State University.

Hewitt, P. L., Flett, G. L., Sherry, S. B., Habke, M., Parkin, M., Lam, R. W., . . Stein, M. B. (2003). The interpersonal expression of perfection: Perfectionistic self-presentation and psychological distress. Journal of personality and social psychology, 84(6), 1303.

Iarovici, D. (2014). Mental health issues and the university student: JHU Press.

Karademas, E. C. (2006). Self-efficacy, social support and well-being: The mediating role of optimism. Personality and Individual Differences, 40(6), 1281-1290.

Kenny, B., \& Hicks, R. (2014). Perfectionism, psychological wellbeing, and maladaptive eating practices.

Kornblum, M., \& Ainley, M. (2005). Perfectionism and the Gifted: A Study of an Australian School Sample. 
International Education Journal, 6(2), 232-239.

Lyubomirsky, S., Dickerhoof, R., Boehm, J. K., \& Sheldon, K. M. (2011). Becoming happier takes both a will and a proper way: an experimental longitudinal intervention to boost well-being. Emotion, 11(2), 391.

McEwan, K., Gilbert, P., \& Duarte, J. (2012). An exploration of competitiveness and caring in relation to psychopathology. British Journal of Clinical Psychology, 51(1), 19-36.

Mikaeili, F. (2010). Studying the psychological well-being of postgraduate students of Urmia

University. Journal of Gonabad University of Medical Sciences and Health Services, 4(16), 65-73.

Miquelon, P., Vallerand, R. J., Grouzet, F. M., \& Cardinal, G. (2005). Perfectionism, academic motivation, and psychological adjustment: An integrative model. Personality and Social Psychology Bulletin, 31(7), 913-924.

O'Connor, R. C. (2007). The relations between perfectionism and suicidality: A systematic review. Suicide and Life-Threatening Behavior, 37(6), 698-714.

Rice, K. G., \& Aldea, M. A. (2006). State dependence and trait stability of perfectionism: A short-term longitudinal study. Journal of Counseling Psychology, 53(2), 205.

Rice, K. G., \& Ashby, J. S. (2007). An efficient method for classifying perfectionists. Journal of Counseling Psychology, 54(1), 72.

Rice, K. G., Richardson, C. M., \& Clark, D. (2012). Perfectionism, procrastination, and psychological distress. Journal of Counseling Psychology, 59(2), 288.

Rice, K. G., \& Stuart, J. (2010). Differentiating adaptive and maladaptive perfectionism on the MMPI-2 and MIPS Revised. Journal of personality assessment, 92(2), 158-167.

Ryan, R. M., \& Deci, E. L. (2001). On happiness and human potentials: A review of research on hedonic and eudaimonic well-being. Annual review of psychology, 52(1), 141-166.

Ryff, C. D. (1989). Happiness is everything, or is it? Explorations on the meaning of psychological well-being. Journal of personality and social psychology, 57(6), 1069.

Ryff, C. D., \& Keyes, C. L. M. (1995). The structure of psychological well-being revisited. Journal of personality and social psychology, 69(4), 719.

Schmutte, P. S., \& Ryff, C. D. (1997). Personality and well-being: Reexamining methods and meanings. Journal of personality and social psychology, 73(3), 549.

Sherry, S. B., Hewitt, P. L., Flett, G. L., Lee-Baggley, D. L., \& Hall, P. A. (2007). Trait perfectionism and perfectionistic self-presentation in personality pathology. Personality and Individual Differences, 42(3), 477-490.

Sin, N. L., \& Lyubomirsky, S. (2009). Enhancing well-being and alleviating depressive symptoms with positive psychology interventions: A practice-friendly meta-analysis. Journal of clinical psychology, 65(5), 467-487.

Sirois, F. M., \& Molnar, D. S. (2016). Conceptualizations of perfectionism, health, and well-being: An introductory overview Perfectionism, Health, and Well-Being (pp. 1-21): Springer.

Slaney, R. B., Rice, K. G., \& Ashby, J. S. (2002). A programmatic approach to measuring perfectionism: The Almost Perfect Scales.

Slaney, R. B., Rice, K. G., Mobley, M., Trippi, J., \& Ashby, J. S. (2001). The revised almost perfect scale. Measurement and evaluation in counseling and development, 34(3), 130.

Stoeber, J. (2012). Perfectionism and performance. Oxford handbook of sport and performance psychology, 
294-306.

Stoeber, J., Feast, A. R., \& Hayward, J. A. (2009). Self-oriented and socially prescribed perfectionism: Differential relationships with intrinsic and extrinsic motivation and test anxiety. Personality and Individual Differences, 47(5), 423-428.

Stoeber, J., Kempe, T., \& Keogh, E. J. (2008). Facets of self-oriented and socially prescribed perfectionism and feelings of pride, shame, and guilt following success and failure. Personality and Individual Differences, 44(7), 1506-1516.

Stoeber, J., \& Otto, K. (2006). Positive conceptions of perfectionism: Approaches, evidence, challenges. Personality and social psychology review, 10(4), 295-319.

Stoeber, J., \& Rambow, A. (2007). Perfectionism in adolescent school students: Relations with motivation, achievement, and well-being. Personality and Individual Differences, 42(7), 1379-1389.

Thorpe, E., \& Nettelbeck, T. (2014). Testing if healthy perfectionism enhances academic achievement in Australian secondary school students.

Trumpeter, N., Watson, P., \& O’Leary, B. J. (2006). Factors within multidimensional perfectionism scales: Complexity of relationships with self-esteem, narcissism, self-control, and self-criticism. Personality and Individual Differences, 41(5), 849-860.

Van Dierendonck, D. (2004). The construct validity of Ryff's Scales of Psychological Well-being and its extension with spiritual well-being. Personality and Individual Differences, 36(3), 629-643.

Wintre, M. G., \& Bowers, C. D. (2007). Predictors of persistence to graduation: Extending a model and data on the transition to university model. Canadian Journal of Behavioural Science/Revue canadienne des sciences du comportement, 39(3), 220. 